\title{
A EDUCAÇÃO JURÍDICA: CRÍTICAS DA CONTEMPORANEIDADE
}

\section{LEGAL EDUCATION: CRITICAL OF CONTEMPORANEITY}

\author{
${ }^{1}$ Patricia Veronica Nunes C Sobral De Souza
}

\section{RESUMO}

Este estudo reflete sobre a Educação Jurídica, considerando as críticas da contemporaneidade. Para alcançar o objetivo, o texto se divide em: Crítica, idealização e realidade da educação jurídica; O professor dos cursos de Direito; A legislação educacional; Questões da metodologia do ensino jurídico; A Pedagogia e o Direito. A leitura das fontes encaminhou o pensamento a inferências sobre $\mathrm{o}$ ensino do Direito, a abordagem metodológica e o preparo didático-pedagógico, segundo a Associação Latino Americana de Metodologia do Ensino do Direito. Contribui-se para a continuidade do debate acadêmico em curso, trata-se de um problema que preocupa os profissionais do ensino superior.

Palavras-chave: Críticas, Contemporaneidade, Educação jurídica, Metodologia

\begin{abstract}
This study reflects on the Legal Education, considering the criticism of contemporaneity. To reach the goal, the text is divided into: Critical, idealization and reality of legal education; Professor of law schools; The educational legislation Questions of legal education methodology; Pedagogy and the law. The reading of the sources referred the thought inferences about the teaching of law, the methodological approach and the didactic- pedagogic preparation, according to Associação Latino Americana de Metodologia do Ensino do Direito. Contributes to the continuity of academic debate in progress, it is a problem that concerns the professional higher education.
\end{abstract}

Keywords: Critical, Contemporaneity, Legal education, Methodology

\footnotetext{
${ }^{1}$ Doutoranda em Direito na Universidade Federal da Bahia - UFBA, Salvador - BA (Brasil). Professora da Universidade Federal de Sergipe - UFS, São Cristóvão - SE (Brasil). E-mail: patncss@ gmail.com
} 


\section{INTRODUÇÃO}

A crítica à educação jurídica está em discussão no Brasil e na América Latina e tem em pauta a distância entre a idealização e o contexto da realidade do ensino e aprendizagem nos cursos de Direito existentes em todo o território nacional. No contexto macro, a crítica repercute sobre o desempenho funcional de formandos em Direito, especialmente ao iniciarem suas práticas nos escritórios de advocacia; e, ainda, sobre o desempenho do profissional do Direito quando se envolve com o magistério, no ensino superior.

Enquanto isto, o mesmo acontece em outros países, mas, com a ressalva de que, nos EUA e na Europa, a situação já se mostra diferente, mais atualizada e comprometida com o social ${ }^{1}$.

Observa-se que, tanto no Brasil, quanto em quase toda a América Latina, há uma educação jurídica apegada ao tradicional, distanciando-se da evolução buscada pelos países mais avançados, que demonstram adequar-se às exigências da sociedade atual e buscam atender às reivindicações das populações desassistidas da proteção da justiça, desrespeitadas na garantia dos seus direitos fundamentais. E esse ensinamento sobre os direitos fundamentais, e essa prática que ensina aos formandos em Direito qual a função social do fazer e do saber dessa ciência.

\footnotetext{
1 A aparente convergência de reformas, dentro e fora dos Estados Unidos, é compatível com o desenvolvimento de ensaios sobre as tendências convergentes e a emergência de "melhores práticas" para a educação jurídica. A maioria dos professores da área do direito tem certeza da superioridade de seus sistemas educacionais. Mas agora essa opinião é quase universal. Os artigos mais consistentes e as inovações mais sérias sobre a educação jurídica fora do país adotam uma abordagem compatível com o programa progressista americano (na América Latina, por exemplo, veja Montoya 2010). E, virtualmente, todos que promovem essas inovações fora dos Estados Unidos foram inspirados pela educação jurídica americana. Na Europa, exemplos proeminentes incluem a Sciences Law School, em Paris (veja Jamin

2012), e a faculdade particular Bucerius, em Hamburgo ("A Bucerius enfatiza o est udo do direito empresarial nacional e internacional - especialmente o europeu e o anglo-americano") (Wenzler and Kwietniewska 2012). As virtudes autoproclamadas da Faculdade Jindal Global se encaixam nessa perspectiva global. De acordo com sua página na internet "A crescente influência do papel da Índia nos assuntos internacionais criou uma forte demanda por juristas altamente treinados, preparados para tratar das questões complexas, enfrentadas pelo mundo atual globalmente conectado." (GARTH, 2014, p. 19). Disponível em: http://bibliotecadigital.fgv.br/dspace/bitstream/handle/10438/12656/Cadernos\%20FGV\%20DIREITO\%2 0RIO\%20-\%20Vol.\%2010.pdf?sequence=1 Acesso em: 10 de fev. de 2016.
} 
Cabe, então, mencionar o papel e a responsabilidade do professorado dos cursos de Direito para a transformação desse contexto de equívocos no qual se forma uma casta de profissionais acima da realidade, desvinculada da problemática e da cultura do próprio país a que serve. Além disto, bate-se, repetidas vezes, sobre a questão da formação para o magistério superior em todas as áreas do conhecimento humano; na questão das metodologias, das estratégias de ensino e aprendizagem; e, na questão do planejamento pedagógico.

Os cursos de Direito não têm o direito de desconhecer a legislação que rege o processo educacional e nem todo o aparato ferramental que prepara para o magistério e para a consecução de uma educação de real qualidade e de resultados satisfatórios. Os acadêmicos do Direito precisam preocupar-se para além das questões das provas da $\mathrm{OAB}$ e, se, por outro lado, divisam no horizonte as perspectivas de se envolverem com a sala de aula, devem para tal saber/fazer se preparar, como o recomenda a LDB (Lei de Diretrizes e base da Educação) nº. 9394/96; precisam conhecer e debater todo o documental de orientação didático-pedagógico-metodológico e envidar esforços no sentido de perceber o que de verdade é mediar o processo ensino-aprendizagem.

O objetivo do presente artigo se propõe a ampliar o debate, pontuando aspectos relativos à educação jurídica. Para tanto, a reflexão foi organizada a partir de 5 (cinco) eixos fundamentais: 1. Crítica, idealização e realidade da educação jurídica; 2. O professor dos cursos de Direito; 3. A legislação educacional; 4. Questões da metodologia do ensino jurídico; 5. A Pedagogia e o Direito. Para cumprir o objetivo, foram consultadas fontes a exemplo das teorias de: ALVES, 2006; BUSSINGUER, 2012; COLAÇO, 2006; COPETTI E MORAIS, 2007; DIAS e MACHADO, 2015; FORTES, 2010; MELGARITO，2013; MENEZES，2013; OLIVEIRA，2014; VARGAS，2013; SANTOS, 2009,11,13,14; VARGAS, 2013; dentre outros.

Justifica-se a elaboração deste estudo pela consciência da necessidade de ingressar no debate sobre a educação jurídica na contemporaneidade, como também, a partir da análise da situação, opinar de forma crítica sobre o contexto em foco, levando também em consideração que esta autora é docente em curso de Direito.

Espera-se contribuir para a construção do conhecimento na área do Direito, como também despertar possíveis leitores desta reflexão para as características do curso de maior demanda no país. Assim, acredita-se plantar uma semente para que floresça a árvore da 
modernidade empenhada em garantir o que prevê a Constituição Federal brasileira: a garantia dos Direitos Fundamentais (individuais).

\section{DESENVOLVIMENTO}

\subsection{Crítica, idealização e realidade da educação jurídica.}

A crítica ao ensino nos cursos de direito é, prioritariamente, centrada na carência de conhecimento e domínio docente sobre o mecanismo de técnicas didáticometodológicas, do planejamento pedagógico e, ainda, da ausência de um projeto político-pedagógico, itens que estão diretamente relacionados aos fazeres, saberes e habilidades dos profissionais da Educação. Além disto, questiona-se a participação do professor e do aluno dos cursos de direito sobre a construção reflexiva de conhecimento e crítica da educação jurídica. Não se pode negar a necessidade de repensar o ensino jurídico, justo por se caracterizar como capaz de mudar mentalidade e exercer reflexos de ordem sócio-político-econômicos importantes para o ser humano. E o que se tem verificado é o crescimento do número de formação de acadêmicos, "profissionais do Direito sem as mínimas condições para o exercício das habilidades em relação às quais o curso propõe-se a capacitar" (CARVALHO, 2010, p. 11).

Por outro lado, o contexto tradicional e tradicionalista no ensino jurídico, vem construindo um muro que o separa da realidade e do compartilhamento com outras áreas do conhecimento humano. Forma-se no seio da sociedade a ideia de uma suposta supremacia/superioridade do mundo jurídico. Outras críticas apontam, quer internas (no âmbito dos cursos de direito), quer externas (em ambientes sociais, mormente nas universidades). Critica-se a falta de entrosamento/comunicação aluno-professor-aluno, falhas no rendimento da aprendizagem, abordagens inadequadas, técnicas desnorteadas, ausência de planejamento ou planejamento equivocado, estratégias mal traçadas e elaboradas sem que seja esboçado um quadro de objetivos claros e bem delineados, preleções arcaicas, reclamações diversas dos alunos, avaliações injustas, desconhecimento da legislação educacional e das novas teorias educacionais, entre outros. Há ainda a considerar o fracasso dos alunos dos cursos de direito no exame da OAB.

As estatísticas que apresentam as notas oficiais relativas à qualidade dos cursos em avaliações realizadas por setores competentes do MEC, do próprio desempenho dos graduandos quando submetidos ao Exame da OAB; e, quanto, em geral, ao desempenho do profissional advogado, à elaboração de documentos; ou ainda, também, 
quando esses advogados exercem a docência nos cursos de Direito, espaço no qual se processa um ensino ultrapassado e desvinculado da realidade. Sobre tal afastamento do real, fundamentando-se em Carvalho (2010, p. 11) adverte-se sobre a necessidade de repensar o ensino jurídico "por ser um processo que provoca mudanças de mentalidade e reflexos sociais, econômicos, políticos, ressalta-se a importância desse processo vital para o desenvolvimento humano".

A qualidade do ensino jurídico do Brasil é assunto que gera desconforto há muitos anos. O modo de ensinar Direito em nosso país pautou-se historicamente por um modelo que está afastado da realidade social concreta, sendo que alunos e professores, em geral, estão presos a "realidades conceituais criadas por eles e que passaram a constituir seu mundo de trabalho" (SANTOS; MORAIS, 2007, p.61).

Não há dúvidas de que a preocupação com o ensino, especialmente o jurídico, vem desde a Antiguidade, quando já os filósofos sofistas se dedicavam a alcançar seus objetivos, isto é, pensavam uma educação centrada no desenvolvimento do indivíduo, assim como se comportam atualmente os advogados, atendendo a uma cultura que prioriza a vitória contra os adversários nas questões processuais "a qualquer custo. Ao passo que o filósofo Sócrates, opositor ferrenho dos sofistas, visava um educar diferenciado, com base na dialética, focado na formação humana, e voltado para o bem da 'Polis' em si mesma" (SOBRAL DE SOUZA, 2013, p. 577).

\section{O PROFESSOR DOS CURSOS DE DIREITO}

Quanto à educação brasileira e, no particular, ao ensino do Direito, não se tem priorizado o professor como mediador de aprendizagem, mas tão somente um professor nos moldes tradicionais e de comportamento altivo, que dita, que ordena que exige, e cuja prática tem, em geral, conduzido a resultados educacionais de pouca ou nenhuma qualidade. Trata-se, portanto, de um ensino e aprendizagem de peso teórico e cujo legado conservador se origina no sistema da secular da

\footnotetext{
Universidade de Coimbra, com suas aulas-conferência, ensino dogmático, mentalidade ortodoxa do corpo docente e discente, a serviço da manutenção da ordem estabelecida e transplantada da ex-metrópole, oportunizando aos profissionais por ele formados o prestígio local e ascensão social (COLAÇO, 2006, p. 15).
} 
Há estudos acadêmicos que analisam as relações de ensino e aprendizagem no ensino jurídico, além de examinarem a prática pedagógica e as relações professor $\times$ aluno $\times$ professor. São pesquisas recentes e que atestam a realidade de docentes quanto à utilização dos

[...] métodos clássicos de ensino, e realmente acreditavam que estavam ensinando, porém, o que se tinha era imposição da matéria e consequentemente um aprendizado falho, porque não dizer deficiente, pois os alunos ficavam de fora do processo de aprendizagem. O professor era visto como autoridade máxima, não sendo permitido fazer interferência de modo de algum no seu modo de transmitir a sua disciplina (MENEZES, 2013, p. 84).

As investigações nos últimos dez (10) anos têm se ampliado qualitativa e quantitativamente na área da educação jurídica, mais notadamente na década de 1980, a partir dos questionamentos críticos de Warat (1980) e de Lyra Filho (1980) reveladores da "necessidade de se pensar o ensino do direito a partir de outros paradigmas teóricos e metodológicos". As ponderações de Dias; Machado (2015, p. 2) estranham o fato de que se observa nos quadros dos três últimos eventos do CONPEDI, uma ampliação de olhar, recorte, metodologia e referencial teórico indicadores de que a "pesquisa no campo da educação jurídica tem dialogado com outros conhecimentos”, entretanto, o "aumento expressivo de produções acadêmicas não tem refletido, em termos mais espraiados, na qualidade social do ensino do direito na graduação".

Contudo, pisa-se firmemente na investigação mais ampla que objetiva mapear e discutir o campo da educação jurídica brasileira, tendo em conta as produções acadêmicas apresentadas e publicadas nos eventos promovidos pelo CONPEDI no período de 2004-2014. Espera-se que tendo conta esse levantamento mais amplo de dados possa-se avançar para uma educação jurídica crítica e de qualidade social (Dias; Machado, 2015, p. 2).

Importante estudo coletivo a respeito da crítica jurídica na América Latina se pregunta sobre o que é a crítica jurídica. E se responde a esta significativa questão a mesma ideia surgida há quarenta anos. Qual o caminho para os juristas críticos? A voz da Crítica Jurídica atualmente engloba múltiplos enfoques e tendências que têm a firme convicção de colocar-se em meio à tensão entre o que o direito é e o que o direito, como ferramenta emancipatória humana, pode vir a ser (MELGARITO, 2013, p.7). 


\begin{abstract}
A educação, mais do que nunca, precisa trabalhar a história e a diversidade de saberes que há no mundo para ser possível a construção de autonomias que sejam prudentes e éticas no seu agir cidadão. Os direitos humanos são um grande resumo e ilustração destes desafios. Não por acaso, inúmeros instrumentos normativos e planos de políticas públicas destacam a Educação em Direitos Humanos como uma exigência de nosso tempo. Grande exemplo é o Plano Nacional de Direitos Humanos 3 - Decreto 7.177/10 que atualizou o Decreto 7.037/09 - que trata da Educação em Direitos Humanos no eixo orientador V - Educação e cultura em Direitos Humanos (VARGAS, 2013, p. 404).
\end{abstract}

Avaliar o contexto tradicionalista e arraigado da educação jurídica na América Latina $^{2}$ é um passo que se deve dar para o reconhecimento da crise da cultura dessa área. A análise que se pretende fazer abrirá espaço para também avaliar e, em seguida, estabelecer uma nova cultura jurídica, fundada na "preparação profissional com consciência social, cidadã", vez que os cursos jurídicos estão pautados em uma "prática pedagógica tecnicista, positivista e hegemônica", e os estudantes têm como objetivo tão somente o diploma em Direito, “almejando galgar carreiras jurídicas, sem o necessário comprometimento com um projeto de vida e social inclusivo, coletivo, que atenda as necessidades dos sujeitos plurais da sociedade do século XXI". Entende-se que, dessa maneira, o Direito continua e continuará sendo uma ciência que atende às necessidades dos indivíduos da elite econômica, deixando os pobres fora da proteção das leis (CAOVILLA; WOLKMER, (2014 p. 2).

No Brasil, tradicionalmente também, os sujeitos estão habituados à realidade de uma justiça setorizada, assim como a que trata das relações de trabalho e da proteção dos direitos trabalhistas, "justamente o exemplo dado por Bourdieu para evidenciar que o “campo jurídico" pode proteger os menos poderosos a partir do momento em que eles ampliam seu poder no "campo social”" (FORTES, 2014, p.187).

\title{
4 A LEGISLAÇÃO EDUCACIONAL
}

Por força da Lei que rege a educação nacional, a (LDB) Lei de Diretrizes e Base $n^{\circ}$ 9.394/96 e mais um complexo conjunto de documentos norteadores do processo do ensino e da aprendizagem, a exigência da formação para o ensino se ampliou e criou um caráter de obrigatoriedade. Dessa forma, nota-se já essa preocupação e um redirecionamento que busca o aperfeiçoamento pedagógico de profissionais de todo o sistema de ensino oficial, incluindo-se o que se refere aos professores universitários. 
Espera-se a gradual mudança do processo de ensino e aprendizagem pautado na ciência da Educação e, por isto mesmo, de mais qualidade.

O presente estudo se debruça sobre questões levantadas por aqueles que buscam compreender como professores e estudantes de Direito conduzem as relações entre ensinar e aprender, cotidianamente; e de que modo o professor do ensino superior, nos cursos de direito, exerce o seu papel de mediador do conhecimento nesse inter- relacionamento. A relação ensinar/aprender não pode ser, a esta altura da evolução sócio educacional e, muito principalmente, considerando-se o avanço das tecnologias, vista como no passado em que o professor detinha desde a primeira à última palavra dentro da sala de aula, era o conhecedor do conteúdo, uma sumidade sobre cuja fala nada se poderia objetar. Era a própria figura do detentor único do saber, não devendo ser questionada em hipótese alguma - situação que se nega ao pensamento científico, que limita o raciocínio e que, em lugar de formar, deforma.

Alguns aspectos do ensino do Direito são indispensáveis à concretização de um projeto de felicidade do ser humano, como reza o texto da Constituição Federal. Esses aspectos se relacionam intimamente com o ideal de felicidade, da formação intelectual do indivíduo e a mesma noção de felicidade prelecionada no ensino jurídico, entre outros. $\mathrm{O}$ conceito e o projeto comunitário de felicidade alimentados pela cultura grega se voltavam à realização de projetos individuais dos cidadãos e "compunham a arquitetura de suas felicidades", mas só se realizaram sob os auspícios de "um processo civilizatório baseado na cultura e na educação" (COPETTI e MORAIS, 2007, p. 13).

2 Quanto aos EUA, o relato estudos e pesquisas na Universidade de Harvard (EUA), Miguel Gualano de Godoy, doutorando em Direito Constitucional pela UFPR, que atualmente realiza estudos e pesquisas na Universidade de Harvard (EUA), narrou a experiência de estudar no exterior, e em uma das melhores universidades do mundo. O método de ensino do Direito na Harvard Law School (e em praticamente todas as Faculdades de Direito dos Estados Unidos) é completamente diferente das tradicionais e majoritárias aulas expositivas e monológicas que se tem no ensino jurídico no Brasil. O método de ensino em Harvard é socrático, baseado em uma discussão promovida e mediada pelo Professor entre ele e seus alunos. Antes de cada aula, os alunos devem ler os livros, textos e casos previamente indicados pelo Professor da disciplina. A aula então é um grande debate sobre cada ponto exposto nos livros e textos e também uma permanente revisão e desafio aos argumentos levantados pelas partes, juízes e cortes nos casos concretos. Dessa forma, a leitura prévia e anterior à aula obriga aos alunos a ler e interpretar sozinhos os livros e textos indicados; durante as aulas eles têm a possibilidade de sanar dúvidas e levantar questões sobre os temas que leram; e ainda têm a chance de ver não apenas como as teorias foram aplicadas nos casos concretos, mas também a oportunidade de destrinchar cada argumento utilizado pelas partes, juízes e cortes na decisão. Tudo isso, sob a orientação, provocação e mediação de um professor especialista na matéria e sob o crivo dos contra-argumentos e diferentes pontos de vistas dos demais colegas de turma. Disponível em: http://www.gazetadopovo.com.br/blogs/dinheiropublico/harvard- breves-impressoes-de-um-pesquisador-visitante/ Acesso em: 10 de fev. 2016. 
Quanto aos aspectos da felicidade nos campos político e jurídico, especificamente no campo político ou da política propriamente, não se distanciam da "situação de tal temática no campo jurídico", quase que totalmente esquecida pelos juristas, cujas preocupações se atêm mais às questões dogmáticas, movimentações processuais cotidianas, “[...] ou com sucessos profissionais no âmbito individual, não menos olvidadas têm sido as múltiplas questões que compõem a complexidade do que se chama felicidade, quando se fala em termos de ensino jurídico. Indique-se, ainda, a objetividade da firmeza da relação entre a Constituição e a educação no conteúdo material da educação no cenário constitucional brasileiro pós-88, conforme previsto no projeto do Estado de Direito, e pelas vias da inclusão dos conteúdos das liberdades, igualdades e solidariedades, o que ilumina a atuação estatal em suas vertentes legislativa, executiva e jurisdicional, da mesma forma que "supõe garantias, prestações ou transformações" (COPETTI e MORAIS, 2007, p. 15-25).

\section{QUESTÕES DA METODOLOGIA DO ENSINO JURÍDICO}

A metodologia do ensino jurídico e a avaliação em Direito se estendem para além da identidade e das características profissionais do professor até o conceito de uma universidade que, durante muito tempo, logrou manter uma aura de romantismo cujo eixo estava sustentado e "destinado à meditação científica", um ambiente em que os professores se distanciavam de questões materiais da vida comum cotidiana, e que, em virtude disto os conservava tão somente "interessados no conhecimento pelo conhecimento, ou seja, não tinham o escopo do lucro permeando suas pesquisas” (SOBRINHO, 1997, p, 129).

Por sua vez, o currículo do curso de Direito é alvo de críticas reveladoras das deficiências e das características de um discurso estereotipado repetido ad nauseam até a divulgação da Resolução n. 3, de 1972, exarada pelo "extinto Conselho Federal de Educação, que se constituiu a direção normativa do ensino jurídico até o ano de 1994” que, em seu artigo $1^{\circ}$, estipula o currículo mínimo estruturado em matérias Básicas e Profissionais (SOBRINHO, 1997, p. 41). 


\section{A PEDAGOGIA E O DIREITO}

Considere-se a possiblidade de (des)construção do ensino jurídico tradicional e solene, consubstanciado naquele contexto de magister dixit e proferido em uma linguagem muitas vezes inentendível, dita à semelhança de uma ladainha, ou entoada como um hino comemorativo do então vigente modelo clássico de compreensão liberal e positivista. Era realidade simbólica do Direito, no século XIX, como acontecia ritualisticamente nas antigas academias de São Paulo e de Olinda (Pernambuco), em aulas de leitura in verbis dos textos da legislação vigente, esperando-se dos estudantes.

[...]a capacidade de interpretação literal da textualidade legal. A letra da lei parece tão sagrada e inviolável quanto a letra das Sagradas Escrituras; não pode ser alterada, violada e deve ser capturada em seu sentido mais originário possível. Eis o princípio da hermenêutica jurídica, a partir da hermenêutica sagrada. O Livro Sagrado? A Bíblia do jurista? O Código, ou o compêndio de legislação (BITTAR, 2006, p. 5).

Esta era a pedagogia professada, a da interpretação ipsis litteris, a aula lustrosa, brilhante, decorativa, magnânima, parada no tempo e no espaço, mas que, na opinião de muitos professores e alunos do século XXI ainda é um ensino que ofereceu e continua oferecendo resultados de qualidade. Entretanto, trata-se de opinião sem lastro científico, sem comprovação, e que consiste apenas no efeito retórico e grandiloquente tão ao gosto daqueles que se impressionam com palavras "bonitas" e figuras grandiloquentes cujos significados e mecanismos desconhecem, mas que soam proféticos e sagrados como o texto bíblico. Assim como o diz Fortes:

\footnotetext{
O ensino jurídico no Brasil possui inúmeros problemas e dentre eles um merece destaque, pois é de ordem pedagógica e, portanto, basilar: o "cuspimento" do saber, ou seja, os ensinamentos passados como dogma e sem possibilidade de serem questionados, pensado". (2010, p. 1)
}

Eminentes estudiosos e mestres do Direito têm seus nomes aureolados de honra, glória e produção de obras até hoje respeitadas e referências na área jurídica, a exemplo de Augusto Teixeira de Freitas, considerado o Jurisconsulto das Américas, o Maior Codificador Brasileiro, filho do Barão de Itaparica, o mais importante jurista brasileiro do séc. XIX; e ainda Carneiro Ribeiro, antigo professor de Ruy Barbosa, no Liceu Baiano. Não se está negando ou renegando o reconhecido valor desses e de outras lentes da área jurídica. Entretanto, urge chegar ao presente, pois o mundo vivencia uma fase de modernização surpreendente e envolvido no panorama criado pelos fatores 
econômicos desencadeados via processo da globalização, pelo avanço das tecnologias e pela abrangência da comunicação e da informação. O mundo novo compartilha a

[...] certeza de que o modelo tradicional de ensino jurídico, baseado na centralidade da figura do professor, no poder do saber, na lógica epistemológica cartesiana, na autoridade docente e na exegese da norma, por meio de intérpretes/doutrinadores sem qualquer formação humanística, não foi e não é capaz de atender às exigências de um mundo cada vez mais complexo e plural (BUSSINGUER, 2012, p. 55-56).

Mesmo que autores, a exemplo de Bussinguer (2012) critiquem o tradicionalismo do ensino jurídico, o que também acontece na educação como um todo, os indivíduos formados nesse modelo ainda jesuítico de ensinar, por mais que se esforcem, não conseguem se libertar do padrão e o transmitem de geração a geração, prejudicando os estudantes em todas as faixas do processo educacional. Como está posto na citação, rejeita-se o paradigma cartesiano abraçado pelos intérpretes e doutrinadores da Lei, sem que, em algum momento, se lhes brote no raciocínio os aspectos humanísticos que os auxiliaria a compreender os mecanismos de funcionamento da nova sociedade, complexa e em si mesma plena de diversidade.

\subsection{Para uma Pedagogia da Educação Jurídica no mundo moderno}

Em outra ponta, e a propósito do argumento de um mundo globalizado, do avanço da tecnologia e do acesso à internet, o Ensino a Distância (EAD) é também motivo de debate, no que tange aos cursos de Direito. O professor do Direito em modalidade à distância precisa assumir a ideia de que "a aprendizagem deve enfatizar a interação entre os indivíduos no processo, isto é, da relação daquele que ensina com aquele que aprende" e pelo aprimoramento constante da prática didático-pedagógica (AFONSO, s/d, p. 32). Acrescenta ainda que

[...] a tutoria virtual no ensino de Direito sem dúvidas expressa que a importância dada pelos professores a um processo de formação virtual, irá garantir uma base conceitual sólida necessária à atuação consistente dentro da abordagem colaboradora, e mais, uma salutar vivência deste processo como alunos, sendo este um caminho para propiciar o processo de "posse" da visão construtivista e de sua consequente aplicação (AFONSO, s/d, p. 40. Disponível em: http://www.egov.ufsc.br/portal/sites/default/files/anexos/29078-29096-1- PB.pdf ). 
A tendência do ensino na era digital é a EAD. Modalidade de ensino nascida nos EUA se espalhou por todos os continentes, permite aos seus alunos estudarem de forma civilizada, organizada, assessorada e avaliada, estando espacial e temporalmente distanciados dos seus professores. Quando há a necessidade, e sob criterioso planejamento, professores e alunos têm aulas presenciais, quando são prestadas orientações para os cuidados, obrigações e trabalhos da disciplina em curso. As aulas virtuais, preparadas com a assessoria de equipes especializadas são da mais reconhecida competência e qualidade. Nesse ambiente da educação a distância, se desenvolve todo um contexto de colaboração, de compartilhamento, de solidariedade que só instigam nos estudantes os princípios éticos e profissionais e a responsabilidade. E, como citado por Afonso, abre-se um espaço de apropriação do conhecimento pelas vias construtivistas.

Ainda quanto à (des) construção do ensino jurídico, enfatiza-se o fascínio exercido pelo Direito Penal e pelos frágeis liames que podem conduzir estudantes de Direito através de "situações emocionantes, com narrativas permeadas de violência e crueldade, capazes de expor a curiosidade humana pela tragédia”. Assim, exempli gratia,

\footnotetext{
A elaboração de uma atividade interdisciplinar na disciplina Direito Processual Penal III e a assunção da perspectiva transdisciplinar no ensino das ciências criminais tem possibilitado a abertura de espaços entre diferentes tempos do conhecimento, entrelaçando, por exemplo, o processo penal, a criminologia e a filosofia. (BOLDT e KHROLING, 2012, p. 31-33).
}

O desacerto didático-pedagógico-metodológico no planejamento e nas aulas dos Cursos de Direito alcançou um ponto em que o ensino jurídico, no Brasil, tornou-se "estigmatizado por duas características que dificultam a formação de profissionais capacitados para o atendimento das necessidades do mercado de trabalho e conscientes da função social do Direito" (BERNARDINA, 2012, p. 1).

As atuais metodologias de ensino têm tomado de exemplo ensinamentos lastrados em uma compreensão da dimensão dialógica do processo educacional e, ainda aos aspectos que envolvem a criação, o questionamento, a análise e a produção do conhecimento que se originam da relação professor-aluno-professor e todo o corpo educacional em macro contextos. Paulo Freire evidenciou a relevância do fator ética e do compromisso político como intrínsecos ao ato educador. Assim, cabe levar às academias a reflexão, o debate e a análise sobre uma metodologia de ensino baseada nas ideias freirianas da pedagogia do oprimido, tendo em vista a "conjuntura em que se apresenta a educação brasileira dos últimos anos" (STANGHERLIM, 2013, p. 10). 
Acerca do direito dos oprimidos, Santos (2014), trata de alavancar a construção do conhecimento no âmbito da teoria do direito e do Estado, e o faz via leitura e releitura dos aspectos relativos ao sistema de dominação existente entre classes sociais, e sob o ponto de vista da sociologia e sobre o pluralismo jurídico. O pluralismo jurídico, no conceito de Rebonatto (2011,p. 1) é o

[...] fenômeno decorrente da complexidade humana, nasce, a partir da inadequação da concepção unitária e centralizadora do direito, e das exigências da nova realidade complexa dos conflitos humanos, baseia-se na existência de mais de uma realidade social, dando atenção às várias formas de ação prática e a complexidade de áreas sociais com características próprias que compõem o mundo jurídico ao qual estamos imersos. Dessa forma essa situação de complexidade nada mais é do que um repaginamento do pensamento jurídico com vistas em uma maior eficácia do poder judiciário dentro de sua atuação prática, levando em consideração principalmente uma visão antidogmática e interdisciplinar que busca a supremacia de considerações ético-sociológicas sobre a realidade puramente positivista do direito.

Boaventura de Sousa Santos (2014) aprecia as estruturas jurídicas do direito de Pasárgada (direito não oficial) e o direito estatal brasileiro (direito do asfalto) e, dessa forma se debruça sobre a realidade das classes oprimidas. A linguagem apurada de Santos o distancia da palavra simples e objetiva de Paulo Freire, mas, o foco permanece o mesmo. O direito de Pasárgada é um exemplo de um sistema jurídico, informal e não oficial, criado por comunidades urbanas oprimidas, que vivem em guetos e bairros clandestinos, para preservar a sobrevivência da comunidade e um mínimo de estabilidade social numa sociedade injusta, onde solvência econômica e a especulação imobiliária determinam o âmbito efetivo do direito à habitação (SANTOS, 2014, p.342).

Aponta uma pergunta: Em que a exposição sobre o direito de Pasárgada se relacionaria com o ensino do Direito? Usemos as palavras do próprio Santos (2013) para oferecer uma resposta, mas não sem antes esclarecer que ensinar é fazer a leitura de mundo, como o propagou Paulo Freire em todo o conjunto de sua obra. A resposta que se encontra em Santos (2013, p. 122) seria a que faz uma leitura do mundo atual, afirmando que "a luta pelos direitos humanos nas primeiras décadas do século XXI enfrenta novas formas de autoritarismo que convivem confortavelmente com regimes democráticos". O que diz Santos, em seu discurso de Doutorado Honoris Causa, 
em 2013), na Universidade de Brasília bem se aplica à atual situação social e política brasileira, tema que deveria estar sendo tratado em todos os cursos de Direito no país.

A criticidade e a emancipação pelas vias da educação libertadora são as tônicas na obra freiriana, e o é também na de Boaventura de Sousa Santos, como o faz em sua obra intitulada "Para uma revolução democrática da justiça". A ideologia freiriana defendia a emancipação dos sujeitos pela leitura de mundo e Santos, ousamos comparar, em outro nível, preconiza a releitura do mundo jurídico pelas vias do acesso à justiça, das inovações institucionais, do ensino do direito e a formação profissional, além de outras recomendações, a exemplo da necessidade de uma revolução nas faculdades de direito, tendo em vista que a realidade é a de um "o paradigma jurídico-dogmático que domina o ensino nas faculdades de direito não tem conseguido ver que na sociedade circulam várias formas de poder, de direito e de conhecimentos que vão muito além do que cabe nos postulados.” (SANTOS, 2011, 86-87).

\subsection{A Educação Jurídica na conjuntura do processo educacional brasileiro}

Os problemas que têm atingido os cursos de Direito fazem parte dessa conjuntura da educação brasileira, fazem tanto que, em virtude da questão da metodologia do ensino do Direito, foi criada a Associação Latino Americana de Metodologia do Ensino do Direito (ALMED), fundada por um professor de Direito da Universidade Federal de Santa Catarina, entidade que funcionou de 1980 a 2000. Tratava-se de uma proposta diferenciada, baseada no amor e no afeto, buscando novas formas de ensino aprendizagem e criticando o método tradicional do ensino jurídico, mas "não se conseguiu a transformação do professor em mestre" (MONDARDO, 2006).

Naturalmente, para além desses aspectos até agora contemplados, há uma gama de abordagens inerentes ao contexto educacional e, para apreendê-los e praticá-los será necessário pesquisar, refletir e debater sobre eles para produzir conhecimento, aplicá-los e avaliá-los até que, tanto os docentes dos cursos de Direito, quanto os de outros cursos superiores se conscientizem que ensinar, além de pressupor talento e dedicação, é também uma arte e uma ciência. Em virtude disto, os professores devem conscientizar- se e refletir sobre as "práticas profissionais cotidianas e voltar continuamente a estudar para aprender a ensinar" (COLAÇO, 2006, p. 8). Neste sentido corrobora Boaventura de Sousa Santos "Para uma pedagogia do conflito" (2009), afirmando que o ensino jurídico permanece inalterado desde a implantação dos primeiros cursos jurídicos, em que os educadores partem do pressuposto enganoso de que o conhecimento do sistema jurídico é Revista de Pesquisa e Educação Jurídica | e-ISSN: 2525-9636 | Brasília | v. 2 | n. 1 | p. 20 - 39 | Jan/Jun. 2016. 
suficiente para a obtenção de êxito no processo de ensino-aprendizagem. Boaventura alerta para a necessidade de integração entre o ordenamento jurídico com as práticas e problemas sociais e que desta forma se consubstanciará o verdadeiro conhecimento jurídico, com o mergulho efetivo do aluno não só nas leis e na codificação, mas também na concepção de mundo que o circunda. (SANTOS, 2009)

Sobre o ensino do Direito e a capacitação/formação docente, fator preponderante nesse contexto é a multiplicidade, "a heterogeneidade dos profissionais da educação do Direito, em cujo meio aparecem o professor profissional e o profissional professor". Cumpre notar quanto à questão da titulação, que ela, em si e por ela mesma, não é "garantia de competência pedagógica" e, o "ensino do Direito tem sido marcado pelo amadorismo, que causa muitos danos a alunos e professores" (COLAÇO, 2006, p. 1314), é o caso do profissional do direito que não possui formação didático-pedagógica.

O obstáculo para que aconteça a harmonia e o congraçamento entre áreas e disciplinas (transversalidade, transdisciplinaridade, multidisciplinaridade e interdisciplinaridade) ocorre quando da formação das matrizes curriculares dos cursos jurídicos. O desenho dessas matrizes tem cerceado a integração dos diversos conteúdos e saberes disciplinares, não apresenta áreas de concentração proporcionadoras da identidade do curso, "dificultando a formação integral e a concepção de totalidade necessária à formação interdisciplinar” (ALVES, 2006).

Todos esses termos oferecem espaços de questionamentos, interpretações equivocadas e outras mais próximas do significado de cada um. A transversalidade se relaciona com os "aspectos formativos da educação, priorizando temas próprios e capitais da cultura em direitos humanos buscando reforçar os vínculos dos indivíduos com valores da cidadania" (OLIVEIRA et al, 2014, p. 4). Por sua vez, a transdisciplinaridade compreende a "busca atual de um novo paradigma para as ciências da educação bem como para outras áreas, como na saúde coletiva, por exemplo” (Almeida Filho, 1997, apud Pires, 1998, p. 4). Quanto à interdisciplinaridade, esclarece Pires (1996), trata-se de um debate iniciado nos anos setenta, oriundo do discurso revolucionário dos estudantes universitários europeus e latino-americanos, e cuja proposta era a crítica ao funcionamento e à estrutura organizacional do ensino universitário e, ainda, a busca pela definição da função que desempenharia o conhecimento no contexto da sociedade capitalista. Isto incluiria a separação entre a teoria e a prática social dos conteúdos escolares. Por essas vias, as 
"instituições responderam a algumas exigências do movimento estudantil iniciando a busca de novos pressupostos que levaram a modificações estruturais e curriculares", promovendo a "superação da superespecialização e da desarticulação teoria e prática, como alternativa à disciplinaridade" (PIRES, 1998, p. 5). A multidisciplinaridade, por sua vez, transmite uma sensação de esgotamento nas tentativas de trabalho docente conjunto, em meio às disciplinas "em que cada uma trata de temas comuns sob sua própria ótica, articulando, algumas vezes bibliografia, técnicas de ensino e procedimentos de avaliação" (PIRES, 1998, p. 4).

\section{CONSIDERAÇÕES FINAIS}

O "milagre" educacional se funda nos princípios da Didática e da Pedagogia acompanhados da produção de conhecimento, da interação ininterrupta com os estudantes, do debate, do exercício consciente e da avaliação que testemunha os resultados considerados de qualidade. Claro está que esses resultados, fora desses princípios regedores da ação docente, só produzem um ensino frustrado, de péssima qualidade e que lançam, na sociedade e no mundo do trabalho, profissionais desqualificados, despreparados para o exercício da profissão que escolheram.

A interdisciplinaridade é uma espécie de ciranda das áreas de conhecimento, um entrelaçamento, um compartilhamento, um dar-se às mãos de forma cooperativa e um produtor de mais e amplos saberes encaminhadores, por sua vez, de novos e renovados fazeres. Dessa forma, cada área dar-se-ia às outras e das outras também receberia, isto é, um diálogo seria formado no qual as contribuições só gerariam mais e mais conhecimentos. A proposta da interdisciplinaridade, entretanto, tem sido vista como difícil, inclusive pelos educadores, acostumados à compartimentalização do saber. Essa dificuldade vem, exatamente, de toda uma história da formação do processo educacional brasileiro em que cada área se isola e se coloca em um pedestal inacessível; ademais, seus membros, a depender de concepções e representatividades, consideram suas áreas como mais importantes, necessárias, indispensáveis e nobres - afastando-se assim as partes constitutivas do saber humano. É como se um cristal fosse fragmentado e as suas peças não pudessem mais se unir. Todas as áreas necessitam do conhecimento linguístico, pois com ele se expressam e produzem mais conhecimentos, não necessariamente pelo excesso de erudição, mas pela objetividade, pela coerência, pela clareza e cientificidade explícita. 
O universo educacional, seja público ou privado, carece mais e mais de inovação em educação, mais precisamente no foco deste estudo, na educação superior, com professores comprometidos e detentores de conhecimentos pedagógicos. Esta carência tem minorado com os cursos de formação para docentes oferecidos pelas instituições públicas e particulares de Ensino Superior e a exigência destas instituições de professores mestres e doutores.

Evidente está na argumentação que se formula neste artigo que ensinar direito o Direito seria uma transformação desse ensino que, como lembraram estudiosos citados no início do texto, era um exercício de autoridade e indiferença com relação aos acadêmicos, tratados como recipientes do conhecimento demonstrado orgulhosamente e até pedantemente pelas suas lentes. Ensinar "direito o Direito" tem, portanto, íntima relação com a ciência da Educação e com seus postulados, teorias, práticas e experimentos, num constante fazer-avaliar-refazer e assim por diante. Por isto mesmo os estudos aqui reunidos propõem a capacitação docente no contexto das políticas para a educação superior, considerando aspectos da metodologia do ensino do Direito, da docência e das questões da interdisciplinaridade como desafio pedagógico, da aprendizagem no Curso de Direito fundamentada na práxis da cidadania, da educação para os direitos humanos, do ensino jurídico por meio da extensão universitária, das alternativas pedagógicas para esse tipo de ensino, e da discussão enquanto técnica de ensino do Direito, aspectos que contribuem sobremaneira para a efetivação do processo ensino-aprendizagem. 


\section{REFERÊNCIAS BIBLIOGRÁFICAS}

AFONSO. Tânia Mara Fonseca Mendes. Ensino à distância no curso de direito: erros e acertos. Disponível em http://www.egov.ufsc.br/portal/sites/default/files/anexos/2907829096-1-PB.pdf.

Acesso 01 abr. 2016.

ALVES, Elisete Lanzoni. A docência e a interdisciplinaridade: Um desafio pedagógico. In COLAÇO, Thais Luzia (org.). Aprendendo a ensinar direito O Direito.

- Florianópolis: OAB/SC Editora, 2006. 344 p.

BERNARDINA, Alexandre Dalla. A utilização de decisões judiciais como estratégia de ensino na disciplina de Responsabilidade Civil. In MIGUEL, Paula Castello; OLIVEIRA, Juliana Ferrari de. Estratégias pedagógicas inovadoras no ensino jurídico. Rio de Janeiro: Lúmen Júris, 2012. 211p.

BITTAR, Eduardo C. B. Estudos sobre ensino jurídico: pesquisa, metodologia, diálogo e cidadania. - 2. ed. Rev., modificada, atual. e ampl. - São Paulo: Atlas, 2006.

$246 \mathrm{p}$.

BOLDT, Raphael e KHROLING, Aloísio. O processo interdisciplinar: (des)construindo o ensino das ciências criminais. In MIGUEL, Paula Castello; OLIVEIRA, Juliana Ferrari de. Estratégias pedagógicas inovadoras no ensino jurídico. Rio de Janeiro: Lúmen Júris, 2012. $211 \mathrm{p}$.

BUSSINGUER, Elda Coelho de Azevedo. Ensino jurídico e aprendizagem significativa: uma tentativa de compreensão da tragédia, do direito e da justiça a partir de uma abordagem fenomenológica. In MIGUEL, Paula Castello; OLIVEIRA, Juliana Ferrari de. Estratégias pedagógicas inovadoras no ensino jurídico. Rio de Janeiro: Lúmen Júris, 2012. 211p.

CARVALHO, Nathalie de Paula. Uma Análise do Ensino Jurídico no Brasil. Disponível em: http://www.fa7.edu.br/recursos/imagens/File/direito/ic2/vi_encontro/Uma_analise_do_e nsino_juridico_no_Brasil.pdf, 2010. Acesso 10 abr. 2016.

CAOVILLA, Maria Aparecida Lucca; WOLKMER, Antonio Carlos. Educação jurídica diante do novo constitucionalismo Latino-americano. Disponível em: http://publicadireito.com.br/artigos/?cod=3a8d959f33298c29. Acesso 01 abr. 2016.

COLAÇO, Thais Luzia. Ensino do direito e capacitação docente. In COLAÇO, Thais Luzia (org.). Aprendendo a ensinar direito O Direito. - Florianópolis: OAB/SC Editora, 2006. 344 p.

COPETTI, André e MORAIS, José Luiz Bolzan de. Ensino do Direito como condição para a concretização de um projeto de felicidade presente na Constituiçã o Federalbrasileira. In SANTOS, André Leonardo Copetti. MORAIS, José Luiz Bolzan de. O ensino jurídico e a formação do bacharel em Direito: diretrizes político-pedagógicas do curso de Direito da UNISINOS. - Porto Alegre: Livraria do Advogado Editora, 2007. $135 \mathrm{p}$. 
DIAS, Renato Duro; MACHADO, Lúcio Carobin. Desafios e potencialidades para o campo da educação jurídica: um "estado da arte". Disponível em: http://repositorio.furg.br/bitstream/handle/1/5426/Desafios $\% 20 \mathrm{e} \% 20$ potencialidades $\% 2$ 0para $\% 20$ o\%20campo\%20da\%20educa $\%$ C3\%A7\%C3\% A3o\%20jur\%C3\%ADdica $\% 20$ um $\% 20 \% \mathrm{E} 2 \% 80 \% 9 \mathrm{Cestado} \% 20 \mathrm{da} \% 20 \mathrm{arte} \% \mathrm{E} 2 \% 80 \% 9 \mathrm{D}$.pdf? sequence=1. Acesso $10 \mathrm{abr}$. 2016.

FORTES, Pedro Rubim Borges et al. Advocacia contemporânea e perspectiva crítica. In: A Formação da Advocacia Contemporânea. Educação e Direito - Volume 10 - 2014. FVG Direito Rio: 2014. Disponível em: http://bibliotecadigital.fgv.br/dspace/bitstream/handle/10438/12656/Cadernos\%20FGV \%20DIREITO\%20RIO\%20-\%20Vol.\%2010.pdf?sequence=1. Acesso 01 abr. 2016.

FORTES, Wanessa Mota Freitas. O problema do ensino jurídico e o desemprego no Brasil. In: Âmbito Jurídico, Rio Grande, XIII, n. 81, out 2010. Disponível em: $<$ http://www.ambitojuridico.com.br/site/index.php?n_link=revista_artigos_leitura\&artigo_id=8542>. Acesso 05 mar. 2016.

FREIRE, Paulo. Pedagogia do Oprimido. 29 ed., Rio de Janeiro: Editora Paz e Terra. 1996. 89 p.

GARTH, Bryant G. As profissões jurídicas no século XXI: globalização, a reforma da educação jurídica, desigualdade e império. In: A Formação da Advocacia Contemporânea. Educação e Direito - Volume 10 - 2014. FVG Direito Rio: 2014. Disponível em: http://bibliotecadigital.fgv.br/dspace/bitstream/handle/10438/12656/Cadernos\%20FGV \%20DIREITO\%20RIO\%20-\%20Vol.\%2010.pdf?sequence=1. Acesso 01 abr. 2016.

MELGARITO, Alma. Pluralismo jurídico: hacia una teoría constitucional latinoamericana. In WOLKMER, Antonio Carlos; CORREAS, Oscar. Crítica Jurídica na América Latina. Aguascalientes: CENEJUS, 2013. 1365 p.

MENEZES, Adriana Maria Celestino. Ensino jurídico no Brasil - Uma questão a ser solucionada. In PESSOA, Flávia Moreira Guimarães (org.). Reflexões sobre a Docência Jurídica. Série Estudos de metodologia. Volume 1 - Aracaju: Evocati, 2013. $654 \mathrm{p}$.

MONDARDO, Dilsa. Metodologia do ensino do Direito: memórias de um cronópio. In COLAÇO, Thais Luzia (org.). Aprendendo a ensinar direito O Direito. - Florianópolis: OAB/SC Editora, 2006. 344 p.

OLIVEIRA, Joaquim Humberto Coelho et al. Temas transversais de formação geral e redes sociais: experiências educacionais inovadoras no ensino superior. Portal UNIGRANRIO. Rio de Janeiro 05/2014. Disponível em: http://www.abed.org.br/hotsite/20-ciaed/pt/anais/pdf/209.pdf. Acesso 01 abr. 2016.

PIRES, Marília Freitas de Campos. Multidisciplinaridade, interdisciplinaridade e transdisciplinaridade no ensino. Interface (Botucatu) [online]. 1998, vol.2, n.2, pp.173-182. ISSN 1807-5762. Disponível em: http://dx.doi.org/10.1590/S141432831998000100010. Acesso 01 abr. 2016. 
REBONATTO, Ligia Kayaline. Pluralismo Jurídico. Disponível em:

http://www.viajus.com.br/viajus.php?pagina=artigos\&id=3557. 15 mar. 2011. Acesso 10 abr. 2016.

SANTOS, André L. C.; MORAIS, José Luis B. de. O ensino jurídico e a formação do bacharel em Direito: diretrizes político-pedagógicas do curso de Direito da UNISINOS. Porto Alegre: Livraria do Advogado, 2007.

SANTOS, Boaventura de Sousa. Para uma pedagogia do conflito, in Freitas, Ana Lúcia e Moraes, Salete Campos (Orgs.), Contra o desperdício da experiência. A pedagogia do conflito revisitada. Porto Alegre: Redes Editora Ltda, 2009.

SANTOS, Boaventura de Sousa. Para uma revolução democrática da justiça. 3ed São Paulo: Cortez, 2011.

SANTOS, Boaventura de Sousa. CHAUÍ, Marilena. Direitos humanos, democracia e desenvolvimento. 1ed São Paulo: Cortez, 2013.

SANTOS, Boaventura de Sousa. O direito dos oprimidos: sociologia crítica do direito. Parte 1. São Paulo: Cortez, 2014.

SOBRAL DE SOUZA, Patrícia Verônica Nunes Carvalho. O Ensino jurídico: Um desafio a ser enfrentado pelos docentes? In PESSOA, Flávia Moreira Guimarães (org.). Reflexões sobre a Docência Jurídica. Série Estudos de metodologia. Volume 1 - Aracaju: Evocati, 2013. 654 p.

SOBRINHO, José Wilson Ferreira. Metodologia do ensino jurídico e a avaliação em direito. Porto Alegre: Sergio Antonio Fabris Editor, 1997. 175p.

STANGHERLIM, Roberta. Metodologia de ensino na concepção de educação de Paulo Freire. In BAPTISTA, Ana Maria Haddad; NOBREGA, Maria Luiza Sardinha de; TODARO, Mônica (orgs.). Metodologias de Ensino: entre reflexão e a pesquisa (Pedagogia de A a Z; vol. 10). Jundiaí, Paco Editorial: 2013. 192 p.

VARGAS, João Pedro Lima De Guimarães. Educação em direitos humanos. In WOLKMER, Antonio Carlos; CORREAS, Oscar. Crítica Jurídica na América Latina. Aguascalientes: CENEJUS, 2013. 1365 p. 